\title{
Comparison of Health-care Waste Management in Urban and Rural Areas in Iran: Application of Multi-criteria Decision Making Method
}

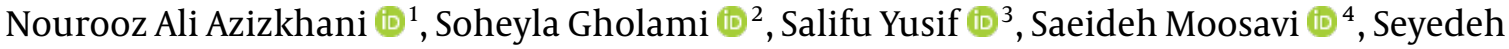 \\ Fatemeh Miri (iD) ${ }^{1}$ and Rohollah Kalhor (iD) ${ }^{1,}$ \\ ${ }^{1}$ Social Determinants of Health Research Center, Research Institute for Prevention of Non-communicable Diseases, Qazvin University of Medical Sciences, Qazvin, Iran \\ ${ }^{2}$ University of Rome Tor Vergata, Rome, Italy \\ ${ }^{3}$ School of Management and Enterprise, University of Southern Queensland, Springfield Queensland, Australia \\ ${ }^{4}$ Occupational Health Department, School of Health, Qazvin University of Medical Sciences, Qazvin, Iran \\ "Corresponding author: Social Determinants of Health Research Center, Research Institute for Prevention of Non-communicable Diseases, Qazvin University of Medical \\ Sciences, Qazvin, Iran. Email: r.kalhor@gmail.com
}

Received 2021 January 26; Revised 2021 May 08; Accepted 2021 May 14.

\begin{abstract}
Background: The global population has grown and is still growing. This growth is happening in more cities than in rural areas, given the continual search for economic opportunities. The implication of this growth is the growth of healthcare centers to meet the growing healthcare demand. Accordingly, healthcare waste production has posed a big challenge to health waste disposal and management.

Objectives: This study aimed to prioritize and select the best method of waste management in the health sector with multi-criteria decision making (MCDM) approaches.

Methods: The present cross-sectional study was carried out to select the best method of managing healthcare wastes through MCDM approaches in Qazvin. The sample was selected and assigned to two groups of 28 experts (five categories) who evaluated the criteria and a group of 22 individuals (four categories) to rank disposal methods of healthcare waste. First, six waste disposal methods and 12 criteria for designing a questionnaire were identified. After designing the questionnaire, the analytic hierarchy process (AHP) was used to calculate the weights of the criteria. Then, the TOPSIS method was used to rank different waste disposal methods. We used EC (ver. 8), Excel (Microsoft, 2007), and Lingo (ver. 14) for analyzing the data.

Results: Concerning the rank of health waste disposal methods based on common existing criteria, urban and rural areas should use different disposal methods. The best disposal methods are irradiation (0.839) and microwave (0.794) in urban areas and steam sterilization (0.867) and microwave (0.840) in rural areas. In both areas, incineration was ranked the last.

Conclusions: To achieve the effective disposal and safety of health waste in urban and rural areas, varied but applicable disposable methods should be used for the management of health waste disposal.
\end{abstract}

Keywords: Health Care Centers, Waste Management, Refuse Disposal, Sanitary Engineering, Multi-Criteria Decision-Making Approach, Waste Disinfection, Medical Waste Disposal

\section{Background}

Hospital waste refers to all infectious and harmful wastes caused by medicines and equipment used in hospitals, health centers, medical diagnostic laboratories, and similar centers, which are considered hazardous waste (1, 2 ). According to the projections of the World Health Organization (WHO), about 75 to $90 \%$ of the waste generated in health centers can be considered safe, but the remaining 10 to $25 \%$ should not be ignored (3). At the global level, especially in low-income countries and most developing countries, waste management is considered a major environmental health challenge (4-6). Despite the new methods of disposal of hospital wastes, there remains a large volume of wastes disposed of through traditional means such as the sanitary landfill. Since recyclable household waste can be converted into urban fertilizers, mixing household and hospital waste threatens human health (7-9). Exposure to these types of wastes can cause diseases such as diarrhea, leptospirosis, typhoid, cholera, AIDS, tuberculosis, and ultimately lead to death (10). About 2.5 million people who have been the victims of illnesses caused by inappropriate waste management die every year (11).

Due to the increasing concern about poor waste management, researchers have developed methods and tools for waste management such as multi-criteria decision 
making (MCDM), multi-objective planning (MOP), and life cycle assessment (LCA) (12). Among them, MCDM is a tool for choosing the best method of waste management among a range of available methods/criteria (13).

A study by Ali et al. (2016) using the LCA method found that the best ways to manage waste were composting, incineration, and sanitary landfill. Another study by Rafei et al. (2016) that used the MCDM method stated hydroclave as the most appropriate technology for treating infectious waste $(14,15)$. In Qazvin province, there were 15 hospitals and about 1370 hospital beds generating about 5,122 kg of hospital waste each day, 1,533 $\mathrm{kg}$ of which were said to be infectious. As such, autoclave-hydroclave and chemiclave were used for the safe handling of wastes $(16,17)$.

\section{Objectives}

With increasing population alongside increased health centers, there has been increasing use of disposable medicines over the past decades. There is a significant increase in health wastes that can cause environmental pollution, negatively impacting human health if not properly managed. The present study aimed at ranking and selecting the best method of waste management in the health sector with MCDM approaches in urban and rural areas.

\section{Methods}

The present study was based on a quantitative method using a survey as the primary means of collecting data in Qazvin province. The research participants consisted of two groups of experts. The first group consisted of 28 experts, belonging to five fields: (1) health deputy experts (HDE); (2) environmental protection agency experts (EPAE); (3) waste management organization experts (WMOE); (4) hospital environmental health experts (HEHE), and (5) faculty members (FM). They were responsible for calculating the weight of the criteria, as well as ranking the methods of garbage disposal in urban areas of the province. The second group consisted of 22 experts in four fields: (1) HDE, (2) EPAE, (3) rural health center experts (RHCE), (4) FM who were responsible for working in rural areas and ranked waste management methods in rural areas. Both groups were included in the study by targeted sampling. The inclusion criteria in the study for selecting the experts were having an education related to the scope of the study and having at least a bachelor's degree and two years of work experience related to health waste management.

First, the factors affecting the disposal of healthcare waste were identified by conducting a literature review.
The authors searched relevant databases, which included but were not limited to Medline and Scopus, and extracted articles for review. The output of this phase included a list of effective factors involved in the disposal of wastes and appropriate methods for the disposal of health and medical waste. This output served as the input for the development of a quantitative data collection instrument. In the next stage, the research instruments, after combining and summarizing the reviews in a few steps, embedded the corrective comments and recommendations from experts and professionals. The developed questionnaires were sent to participants for responding. Finally, we affirmed factors collected based on a statistical analysis of data of the initial questionnaire, in the form of a paired comparison questionnaire, and their validity using the opinion of professors and experts in terms of its form and reliability based on the inconsistency rate of 0.013 . The output of this stage determined the weight of each of the 12 criteria. The research was approved as a master's thesis by the ethics committee of Qazvin University of Medical Sciences with a code of ethics (IR.QUMS.REC.1396.462).

\subsection{Data Analysis}

In this study, a hierarchy process method was used to measure the weight of the criteria. However, in the analytic hierarchy process (AHP), the environment maker cannot express his certain preferences, but can make a judgment based on feeling and understanding (18). In other words, this approach cannot properly reflect the uncertainty in human thought. In fuzzy sets, a proportion is given to a decision-maker, and a fuzzy number is defined by a membership set. Here, the membership function defines the degree to which the elements belong to the set of preferences in a judgment space (19). Therefore, in this study, the fuzzy AHP was used to determine the weights of criteria. The experts' answers to paired comparisons were based on verbal terms on a 9-point Likert scale, and so it was necessary to convert the responses analytically.

After converting the experts' judgments into fuzzy numbers, the experts' judgments were then combined. To combine experts' judgments, Buckley's proposed method was used. According to Buckley's statement, the following formulas (equation 1) were used for combining expert's judgments ( $\mathrm{N}$ experts) $(17,20)$ in which Uij is a triangular fuzzy number.

$$
\begin{aligned}
U_{i j} & =\left(l_{i j}, m_{i j}, u_{i j}\right) \\
& : l_{i j} \\
& \leq m_{i j} \\
& \leq u_{i j} \epsilon\left[\frac{1}{9.9}\right]
\end{aligned}
$$


$l_{i j}=\min \left(B_{i j}\right)$

$m_{i j}=\sqrt[n]{\prod_{1}^{n} B_{i j n}}$

$u_{i j}=\max \left(B_{i j n}\right)$

Where $\mathrm{B}_{\mathrm{ijn}}=$ pairwise comparison between criteria $\mathrm{i}$ and $\mathrm{j}$ evaluated by the nth expert.

Before the weights of the criteria were calculated using Fuzzy AHP, the inconsistency ratio was measured. The maximum acceptable value of the inconsistency ratio is 0.1 when the number of criteria is more than four criteria.

After ensuring the acceptability of the inconsistency rate of the data, Chang's Extent Analysis (EA) method was used to calculate the weight of the criteria as one of the most popular and effective methods for solving the fuzzy hierarchy.

Finally, after calculating the weights of the criteria, the TOPSIS method was used separately in urban and rural areas to rank different methods of waste disposal in the health sector. It is one of the best multi-criteria decisionmaking models. In this method, $\mathrm{m}$ alternatives (here, waste disposal methods) are evaluated by $n$ indices in the form of a decision matrix. This technique is based on the concept that the selected alternative should have the minimum distance with the ideal solution (the best possible state, $\mathrm{A}_{\mathrm{I}}^{+}$) and the maximum distance with the ideal negative solution (the worst possible state, $A_{I}^{+}$) [19]. One of the advantages of using this method (MCDM) in prioritizing health waste disposal methods is the use of the opinion of a large number of experts in this field with various approaches in the field of health waste disposal.

The questionnaires were distributed to the selected sample in person, and the necessary explanations were given on how to complete the questionnaires. To analyze the data of the questionnaires, Expert Choice (EC) software (ver. 8) support, designed by Saaty et al. (21), Excel (Microsoft, 2007), and Lingo (ver. 14) software were used.

\section{Results}

Among 28 participants who participated in urban waste management practices, 17 of them were men (60.7\%), and 11 were women (39.3\%). The mean age of participants was $36.9 \pm 6.0$; the mean work experience was $13.3 \pm 6.8$ years, and their experience in the current position was 9 \pm 6.9 years. Most participants had a bachelor's degree (15 individuals, 53.6\%). Participants in rural areas included 12 men (54.5\%) and 10 women (45.5\%). The mean age of the participants was $36.6 \pm 6.2$; the mean work experience was

\begin{tabular}{|c|c|c|}
\hline Variables & Urban Areas & Rural Areas \\
\hline \multicolumn{3}{|l|}{ Gender } \\
\hline Men & $17(60.7)$ & $12(54.5)$ \\
\hline Women & $11(39.3)$ & $10(45.5)$ \\
\hline \multicolumn{3}{|l|}{ Degree } \\
\hline BSc. & $15(53.5)$ & $13(60)$ \\
\hline MSc. & $10(35.8)$ & $5(22.7)$ \\
\hline Ph.D. & $3(10.7)$ & $4(18.2)$ \\
\hline \multicolumn{3}{|l|}{ Field of study } \\
\hline Environmental health engineering & $24(85.8)$ & $16(72.7)$ \\
\hline Healthcare services management & $2(7.1)$ & $4(18.18)$ \\
\hline Natural resources engineering & $2(7.1)$ & $2(9.09)$ \\
\hline
\end{tabular}

${ }^{\mathrm{a}}$ Values are expressed as No. (\%).

$10.4 \pm 5.9$ years, and their experience in the current position was $8 \pm 5.6$ years (Table 1 ).

The results of weighting the criteria after data analysis are reported in Table 2. The opinion of the five expert groups on the weight of the criteria was the highest in terms of the criteria of air pollutants and environmental impacts, and the cost had the lowest weight. Meanwhile, the inconsistency rate at this stage was 0.013 (Figure 1).

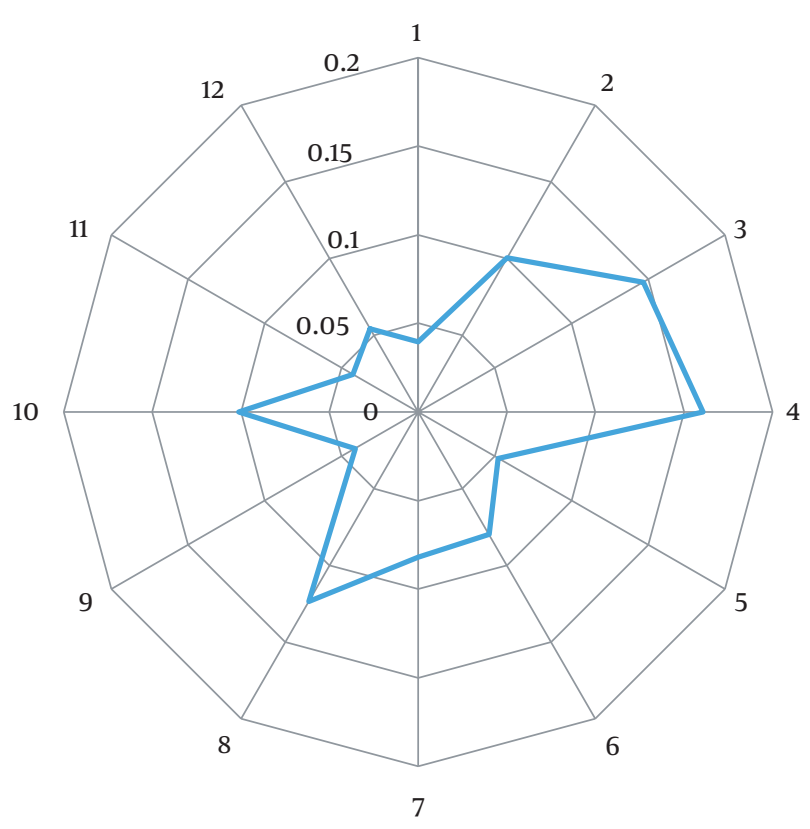

$\overline{\text { Figure 1. Mean score of each criterion according to the experts through MCDM ap- }}$ proach 
Azizkhani NA et al.

\begin{tabular}{|c|c|c|c|c|c|c|c|c|}
\hline \multirow{2}{*}{ Code } & \multirow{2}{*}{ Criteria } & \multicolumn{7}{|c|}{ Groups } \\
\hline & & HDE & FM & EPAE & HEHE & WMOE & Total & Rank \\
\hline 1 & Cost & 0.03 & 0.014 & 0.105 & 0.03 & 0.046 & 0.0395 & 12 \\
\hline 2 & $\begin{array}{l}\text { Solid residuals and environmental } \\
\text { impacts }\end{array}$ & 0.081 & 0.124 & 0.089 & 0.115 & $0 . .179$ & 0.1005 & 5 \\
\hline 3 & $\begin{array}{l}\text { Water residuals and environmental } \\
\text { impacts }\end{array}$ & 0.145 & 0.186 & 0.136 & 0.219 & 0.175 & 0.1465 & 2 \\
\hline 4 & $\begin{array}{l}\text { Air residuals and environmental } \\
\text { impacts }\end{array}$ & 0.165 & 0.178 & 0.154 & 0.08 & 0.203 & 0.016075 & 1 \\
\hline 5 & Odor & 0.05 & 0.035 & 0.045 & 0.028 & 0.033 & 0.05225 & 9 \\
\hline 6 & Release with health effects & 0.055 & 0.125 & 0.125 & 0.087 & 0.081 & 0.07075 & 7 \\
\hline 7 & Reliability & 0.096 & 0.07 & 0.042 & 0.075 & 0.039 & 0.08175 & 6 \\
\hline 8 & Treatment effectiveness & 0.169 & 0.073 & 0.14 & 0.102 & 0.064 & 0.1235 & 3 \\
\hline 9 & Level of automation & 0.034 & 0.025 & 0.047 & 0.021 & 0.031 & 0.041 & 11 \\
\hline 10 & $\begin{array}{l}\text { Occupational hazards occurrence } \\
\text { frequency }\end{array}$ & 0.099 & 0.088 & 0.097 & 0.121 & 0.076 & 0.10125 & 4 \\
\hline 11 & Public acceptance obstacles & 0.031 & 0.04 & 0.021 & 0.04 & 0.033 & 0.04275 & 10 \\
\hline 12 & Land requirement & 0.045 & 0.042 & 0.024 & 0.083 & 0.039 & 0.054 & 8 \\
\hline - & Inconsistency ratio & 0.04 & 0.08 & 0.1 & 0.07 & 0.06 & 0.013 & - \\
\hline
\end{tabular}

The weights obtained in the hierarchical analysis process were used to rank the TOPSIS waste disposal methods in both urban and rural areas. The results of the TOPSIS method according to five groups of health experts to prioritize the best method of waste disposal in urban areas are shown in Table 3.

Using the geometric mean method, the mean of the priorities of disposal methods stated by experts was ranked. The final ranking based on the criteria studied in urban areas are as follows: (1) Irradiation, (2) microwave, (3) steam sterilization (autoclaving), (4) chemical disinfection, (5) sanitary landfill, and (6) finally incineration (Figure 2).

The results of the TOPSIS method based on four expert groups to prioritize the best method of waste disposal in rural areas are shown in Table 4.

The final result of ranking based on the criteria used in rural areas are as follows: (1) steam sterilization (autoclave), (2) microwave, (3) irradiation, (4) chemical disinfection, (5) sanitary landfill, and finally (6) incineration (Figure 3$)$.

\section{Discussion}

This study aimed to investigate different options of hospital waste managers in Qazvin province to select the best method of waste disposal using the multi-criteria decision-making process. Since decision-making is challenging, assessing the alternatives of management methods of hospital wastes requires the consideration of multiple contradictory criteria according to the opinion of

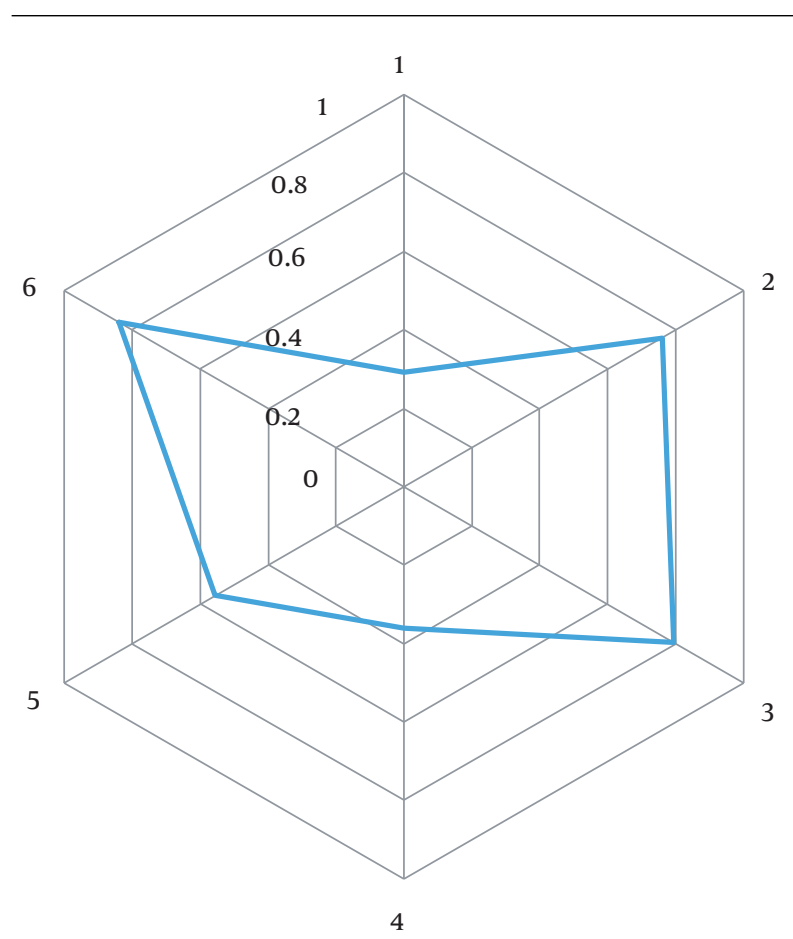

Figure 2. Ranking waste disposal methods according to the expert group using TOPSIS method in urban areas

the expert group. The importance of forming a group to achieve a satisfactory decision is increasing day by day (22).

In this study, to prioritize the methods of waste disposal, 12 different criteria were obtained. The participants allocated the highest weight to the three criteria, includ- 
Azizkhani NA et al.

\begin{tabular}{|c|c|c|c|c|c|c|c|c|c|}
\hline \multirow{2}{*}{ Code } & \multirow{2}{*}{ Alternatives } & \multicolumn{8}{|c|}{ Groups } \\
\hline & & HDE & FM & & EPAE & & WMOE & Total & Rank \\
\hline 1 & Incineration & 0.14677 & 0.58691 & & 0.33150 & & 0.73842 & 0.29318 & 6 \\
\hline 2 & $\begin{array}{c}\text { Steam } \\
\text { sterilization }\end{array}$ & 0.5693 & 0.47781 & & 0.82836 & & 0.56444 & 0.75934 & 3 \\
\hline 3 & Microwave & 0.52756 & 0.48348 & & 0.94077 & & 0.65640 & 0.79408 & 2 \\
\hline 4 & $\begin{array}{l}\text { Sanitary } \\
\text { landfill }\end{array}$ & 0.60466 & 0.48751 & & 0.14989 & & 0.16812 & 0.35990 & 5 \\
\hline 5 & $\begin{array}{l}\text { Chemical } \\
\text { disinfection }\end{array}$ & 0.49162 & 0.42069 & & 0.55257 & & 0.44577 & 0.55447 & 4 \\
\hline 6 & Irradiation & 0.68275 & 0.40573 & & 0.82105 & & 0.50159 & 0.83974 & 1 \\
\hline \multirow{2}{*}{ Code } & \multirow{2}{*}{ Alternatives } & \multicolumn{8}{|c|}{ Groups } \\
\hline & & HDE & & FM & & EPAE & RHCE & Total & Rank \\
\hline 1 & Incineration & 0.007 & & 0.3621 & & 0.1959 & 0.0100 & 0.08998 & 6 \\
\hline 2 & $\begin{array}{c}\text { Steam } \\
\text { sterilization }\end{array}$ & 0.5601 & & 0.7461 & & 0.7490 & 0.9303 & 0.8679 & 1 \\
\hline 3 & Microwave & 0.9999 & & 0.7748 & & 0.8632 & 0.7187 & 0.8402 & 2 \\
\hline 4 & Sanitary landfill & 0.1680 & & 0.3572 & & 0.1728 & 0.5871 & 0.3236 & 5 \\
\hline 5 & $\begin{array}{l}\text { Chemical } \\
\text { disinfection }\end{array}$ & 0.5014 & & 0.3717 & & 0.5574 & 0.6779 & 0.5341 & 4 \\
\hline 6 & Irradiation & 0.8357 & & 0.6783 & & 0.8014 & 0.8073 & 0.8291 & 3 \\
\hline
\end{tabular}

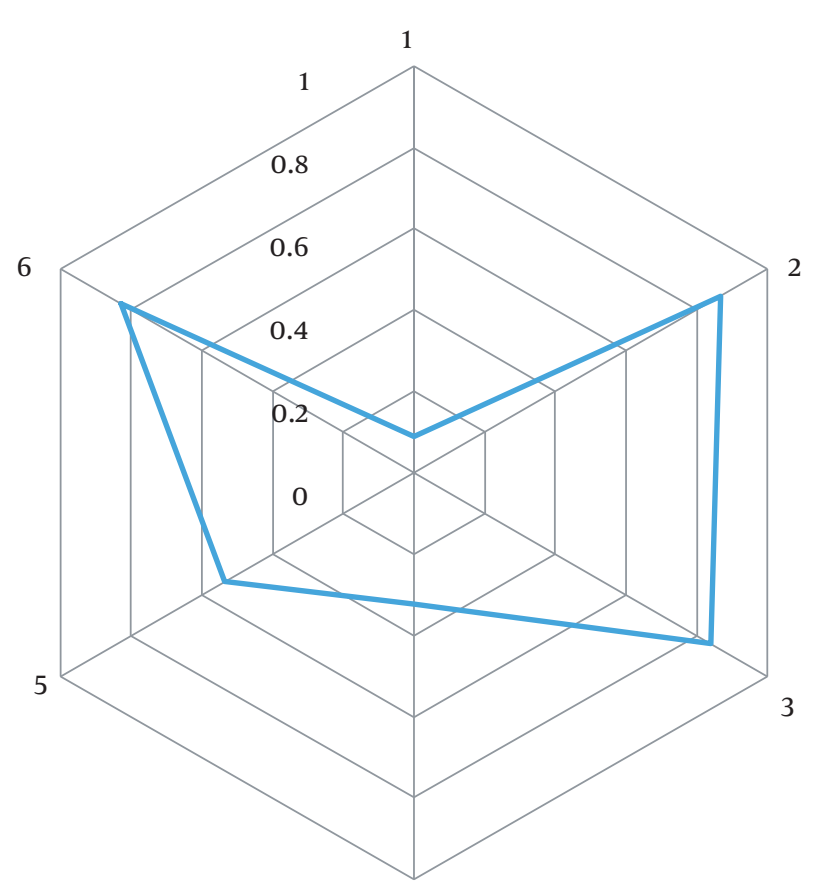

4

Figure 3. Ranking waste disposal methods according to the expert group using TOPSIS method in rural areas

ing Air residuals and environmental impacts, Water resid- uals and environmental impacts, and the Treatment effectiveness, respectively, and the three criteria of costs, level of automation, and Public acceptance obstacles gained the least weigh. In the study by Rezapur et al. who prioritized waste disposal methods in Tehran hospitals, three criteria of the effectiveness of the action, Air residuals, environmental impacts, and barriers to public acceptance, gained the highest weights, and three criteria of costs, odor, and discharge had the least health effects (22).

The ranking of different methods of hospital waste disposal was reported based on the above criteria in different urban and rural areas. In urban areas, the best methods were irradiation, microwave, steam sterilization (autoclave), chemical disinfection, sanitary landfill, and ultimately, incineration, while in rural areas, they were steam sterilization (autoclave), microwave, irradiation, chemical disinfection, sanitary landfill, and eventually incineration.

Irradiation was chosen as the best method in urban areas. The irradiation method has the power of penetration into waste packages and containers. Fatal ultraviolet rays are also used as an additional method to destroy airborne microorganisms, along with other methods, except that there is no penetration power to waste packages (23). In rural areas, steam sterilization (autoclave) was selected as the best method. In a study by Dursun et al. (24) and Chen Liu et al. (25), steam sterilization was selected as the most appropriate waste disposal method. The waste disposal method in rural areas in these studies confirms the findings of the present study. The autoclave method is one 
of the best disposal methods since it has the least impact on the environment and represents a commitment to public health.

The microwave method had second place in urban and rural areas. In a study by Mehdi Hasan et al. (26), the microwave was described as the second method of waste disposal, which confirms the findings of the present study. Also, in a study conducted in Istanbul, the microwave had a second place (24). The microwave method is one of the most used methods to safely dispose of sanitary and medical waste, which reduces the volume of waste and is also suitable for unspecified waste materials. However, it requires a high initial investment and is not suitable for all waste materials. It should be noted that in Iran, the highest amount of healthcare waste produced in urban occurs in hospitals, which is not properly managed concerning the disposal of hazardous waste in these centers (27).

The effectiveness of incinerators as a waste disposal method has been reported with a different result. In this study, the waste incineration method had the last place in both urban and rural areas. The findings of this study are consistent with that of Najaf Abadi et al., who prioritized waste disposal by the AHP method, in which waste incinerators had the last place (28). On the contrary, the results of studies show that waste incineration was selected as the best way of waste disposal in some countries (6). In a study that was conducted at hospitals in Shanghai, incineration had the last place in ranking (25). Although the waste incineration method has long been used as a standard method, due to the lack of methods for controlling air pollution at the outlet of chimneys and the possibility of contaminating the environment, the tendency toward the non-incineration methods and upgrading the methods of disposal can be effective in improving the management of hospital waste disposal, as shown also in this study (29). The results of this study showed that in the studied groups, the best methods for the disposal of waste in both urban and rural areas of Qazvin province were irradiation and steam sterilization, in sequence. For the health care waste disposal in Qazvin province, Autoclave, hydroclave, and chemiclave methods are now being used that products manufactured domestically or imported. In rural areas, methods such as sanitary landfills and incineration are also still being used. Finally, it is suggested that the necessary infrastructure for each of the selected methods in urban areas (irradiation) and rural areas (steam sterilization) be provided by health officials in the province to manage health waste disposal in a standard and safe manner. The strength of this study was to identify the best methods of health waste disposal in urban and rural areas based on the opinions of experts in this field. The limitation of this study was that only experts from this province were used to weigh the criteria and methods of waste disposal. It is suggested that national experts be used in future studies.

\section{Acknowledgments}

The authors acknowledge all experts of Qazvin University of Medical Sciences who kindly participated in the research and completed questionnaires.

\section{Footnotes}

Authors' Contribution: R. K., S.Gh., and NA.A. planned the study; SM and SFM conducted the survey; R. K. and SFM analyzed the data, and R. K. , S.Y., and S. Gh. drafted the article and submitted it.

Conflict of Interests: The authors declare no conflict of interest.

Ethical Approval: The Ethics committee of Qazvin University of Medical Sciences approved the study protocol (ID: IR.QUMS.REC.1396.462).

Funding/Support: The authors received financial support from Qazvin University of Medical Sciences.

\section{References}

1. Pal A, Gin KY, Lin AY, Reinhard M. Impacts of emerging organic contaminants on freshwater resources: Review of recent occurrences, sources, fate and effects. Sci Total Environ. 2010;408(24):6062-9. doi: 10.1016/j.scitotenv.2010.09.026. [PubMed: 20934204].

2. Botelho A. The impact of education and training on compliance behavior and waste generation in European private healthcare facilities.J Environ Manage. 2012;98:5-10. doi:10.1016/j.jenvman.2011.12.003. [PubMed: 22325637].

3. Yves Chartier JE, Pieper U, Prüss A, Rushbrook P, Stringer R, Townend $\mathrm{W}$, et al. Safe management of wastes from health care activities. Geneva, Switzerland: World Health Organization; 2013.

4. Lanyuy GD, Jane FA, Wilfred FM. Medical waste management and disposal practices of health facilities in Kumbo East and Kumbo West health districts. Int J Med Med Sci. 2017;9(1):1-11. doi: 10.5897/ijmms2016.1272.

5. Gillian Dzekashu L, Akoachere JF, Mbacham WF. Medical waste management and disposal practices of health facilities in kumbo east and kumbo west health districts. J Environ Health Sci. 2016;2(6):1-9. doi: 10.15436/2378-6841.16.990.

6. Ali M, Wang W, Chaudhry N, Geng Y. Hospital waste management in developing countries: A mini review. Waste Manag Res. 2017;35(6):58192. doi: 10.1177/0734242X17691344. [PubMed: 28566033].

7. Sawalem M, Selic E, Herbell JD. Hospital waste management in Libya: A case study. Waste Manag. 2009;29(4):1370-5. doi: 10.1016/j.wasman.2008.08.028. [PubMed: 19036572].

8. Jahandideh S, Jahandideh S, Asadabadi EB, Askarian M, Movahedi MM, Hosseini S, et al. The use of artificial neural networks and multiple linear regression to predict rate of medical waste generation. Waste Manag. 2009;29(11):2874-9. doi: 10.1016/j.wasman.2009.06.027. [PubMed: 19643591].

9. Xie R, Li WJ, Li J, Wu BL, Yi JQ. Emissions investigation for a novel medical waste incinerator. J Hazard Mater. 2009;166(1):365-71. doi: 10.1016/j.jhazmat.2008.11.029. [PubMed:19111396]. 
10. Mato RRAM, Kassenga GR. A study on problems of management of medical solid wastes in Dar es Salaam and their remedial measures. Resour Conserv Recy. 1997;21(1):1-16. doi: 10.1016/s0921-3449(97)000104.

11. Chartier Y. Safe management of wastes from healthcare activities. Geneva, Switzerland: World Health Organization; 2014.

12. Zamali T, Lazim MA, Osman MTA. A new fuzzy multi-criteria decision making approach for municipal solid waste disposal options. J Sustain Sci Manag. 2009;4(1):20-37.

13. Tran LT, Knight CG, O’Neill RV, Smith ER, Riitters KH, Wickham J. Fuzzy decision analysis for integrated environmental vulnerability assessment of the mid-Atlantic Region. Environ Manage. 2002;29(6):845-59. doi: 10.1007/s00267-001-2587-1. [PubMed: 11992175].

14. Ali M, Wang W, Chaudhry N. Application of life cycle assessment for hospital solid waste management: A case study. J Air Waste Manag Assoc. 2016;66(10):1012-8. doi: 10.1080/10962247.2016.1196263. [PubMed: 27268967].

15. Rafiee A, Yaghmaeian K, Hoseini M, Parmy S, Mahvi A, Yunesian M, et al. Assessment and selection of the best treatment alternative for infectious waste by modified Sustainability Assessment of Technologies methodology. J Environ Health Sci Eng. 2016;14:10. doi: 10.1186/s40201016-0251-1. [PubMed: 27239313]. [PubMed Central: PMC4884406].

16. Nori M, Nadafi K, Sabaghian M. Evaluate the performance of infectious waste incinerators in Qazvin in 2010 based on HTA. Sixteenth $\mathrm{Na}$ tional Conference on Environmental Health. Tabriz, Iran. Civilica; 2013.

17. Kalhor R, Kiaei M, Mohebbifar R, Shah Bahrami E, Mafi L, Kalhor L, et al. Prioritizing the options for health-care waste man-agement in Qazvin: Using a multi-criteria decision making approach.JBiol Today's World.2016;5(6). doi:10.15412/j.jbtw.01050603.

18. Sun CC, Lin GTR. Using fuzzy TOPSIS method for evaluating the competitive advantages of shopping websites. Expert Syst Appl. 2009;36(9):11764-71. doi:10.1016/j.eswa.2009.04.017.

19. Sheikh MJ, Khodamoradi S, Jalilzadeh M. [Performance evaluation of brokerage firms of Tehran stock exchange using fuzzy AHP and TOPSIS]. Vision of Financial Management and Accounting. 2011;3:83-105. Persian.
20. Nguyen AT, Nguyen LD, Le-Hoai L, Dang CN. Quantifying the complexity of transportation projects using the fuzzy analytic hierarchy process. Int J Proj Manag. 2015;33(6):1364-76. doi: 10.1016/j.ijproman.2015.02.007.

21. Saaty TL. Decision making for leaders: The analytic hierarchy process for decisions in a complex world. 3rd ed. Pittsburgh, Pennsylvania: RWS Publications; 2014.

22. Rezapour A, Arabloo J, Alipour V, Akbari A. [Prioritization of different options for management of hospital wastes in Tehran, Iran, using multi-criteria decision analysis]. Health System Research. 2017;13(1):3845. Persian.

23. Chartier Y, Emmanuel J, Pieper U, Prüss A, Rushbrook P, Stringer R, et al. Safe management of wastes from healthcare activities. 2nd ed. Geneva, Switzerland: World Health Organiztion; 2013.

24. Dursun M, Karsak EE, Karadayi MA. A fuzzy MCDM approach for health-care waste management. International Journal of Industrial and Manufacturing Engineering. 2011;5(1):176-82.

25. Liu HC, Wu J, Li P. Assessment of health-care waste disposal methods using a VIKOR-based fuzzy multi-criteria decision making method. Waste Manag. 2013;33(12):2744-51. doi: 10.1016/j.wasman.2013.08.006. [PubMed: 24011433].

26. Hasan MM, Rahman MH. Assessment of healthcare waste management paradigms and its suitable treatment alternative: A case study. J Environ Public Health. 2018;2018:6879751. doi: 10.1155/2018/6879751. [PubMed: 30151013]. [PubMed Central: PMC6087569].

27. Rabeie OL, Miranzadeh MB, Fallah SH, Dehqan S, Moulana Z, Amouei A, et al. Determination of hospital waste composition and management in Amol City, Iran. Health Scope. 2012;1(3):127-31. doi: 10.17795/jhealthscope-6305.

28. Asgarian Najafabadi SA, Ghassemzadeh HR. [Prioritization of waste disposal methods using analytical hierarchy process]. Environ Sci Technol. 2016;18(3):407-14. Persian.

29. Banaie Ghahfarokhi B, Sadeghi M, Jazayeri SR, Sakinia N. [The study of applicable ways for hospital waste disposal using SWOT method].J Shahrekord Univ Med Sci. 2013;14(6):60-71. Persian. 